УДК 331.5

DOI: $10.18101 / 2304-4446-2021-2-3-10$

\title{
ВЛИЯНИЕ ЦИФРОВИЗАЦИИ ЭКОНОМИКИ НА РЫНОК ЗАНЯТОСТИ В ИРКУТСКОЙ ОБЛАСТИ
}

\section{(C) Аксенюшкина Елена Владимировна}

кандидат физико-математических наук, доцент кафедры математических методов и цифровых технологий

aks.ev@mail.ru

\section{(C) Мамонова Наталья Вячеславовна}

кандидат физико-математических наук, доцент

кафедры математических методов и цифровых технологий naamm@mail.ru

\section{(C) Аксенюшкин Александр Владимирович}

аспирант кафедры математических методов и цифровых технологий aksalekshd@gmail.com

Байкальский государственный университет

Россия, 664003, г. Иркутск, ул. Ленина, 11

Аннотация. Современная экономика идет по пути широкого использования цифровых технологий, полностью изменяющих многие бизнес-процессы. Наиболее актуальным является исследование влияния цифровизации на рынок труда, в частности на уровень занятости и безработицы населения. Одним из основных моментов исследования является то, что с помощью корреляционного анализа возможно выделить основные факторы, характеризующие процесс цифровизации экономики, определяющие уровень занятости населения Иркутской области. Для прогнозирования поведения рынка труда используется анализ временных рядов. На основе проведенного эконометрического исследования удалось выявить элементы цифровизации, которые оказывают наиболее сильное влияние на изменение уровня занятости населения Иркутской области. Проведенный анализ данных позволил показать несостоятельность гипотезы об отрицательном влиянии цифровой трансформации экономики на уровень занятости населения.

Ключевые слова: рынок занятости, уровень безработицы, цифровизация экономики, эконометрическая модель, регрессионный анализ, факторы влияния

\section{Для цитирования}

Аксенюшкина Е. В., Мамонова Н. В., Аксенюшкин А. В. Влияние цифровизации экономики на рынок занятости В Иркутской области // Вестник Бурятского государственного университета. Экономика и менеджмент. 2021. № 2. С. 3-10.

Начало цифровой трансформации бизнеса было связано зачастую только с переносом и хранением собранных данных в цифровой формат, а также переходом медиа в онлайн-пространство. На сегодняшний день цифровизация бизнеса расширяет свои горизонты, теперь информационные технологии внедряются во все 
сферы экономики, которые оставались неизменными многие десятилетия. Совершенно естественно, что этот процесс оказывает влияние на рынок труда.

Изменения такого плана порождают необходимость в исследованиях влияния цифровой трансформации на рынок труда, вне зависимости от того, происходит ли появление новых профессий на рынке труда или же уменьшение количества рабочих мест, что порождает увеличение структурной безработицы.

Оглянувшись на несколько десятилетий назад, человечество даже не могло представить, что интернет и сотовая связь станут одними из самых доступных и распространенных цифровых технологий в настоящее время. Анализ происходящих изменений в экономическом секторе показывает, что в зависимости от уровня развития экономики процесс цифровизации ведет либо к технологической безработице, либо с развитием новых технологий позволяет облегчить человеческий труд, что расширяет границы человеческой деятельности за счет развития творчества и креативности. Поэтому исследование, проводимое с целью спрогнозировать возможное влияние такого процесса на развитие рынка труда, становится достаточно актуальным на сегодняшний день.

Страны с развитой экономикой воспринимают цифровизацию как необходимый процесс, дающий еще больше преимуществ для увеличения экономического роста. Одним из показателей развития экономической системы является рынок труда. На сегодняшний день существует большое количество факторов, которые оказывают влияние в той или иной степени на эту экономическую структуру, выделим из них наиболее существенные: демография, глобализация и цифровизация (рис. 1) [1-3].

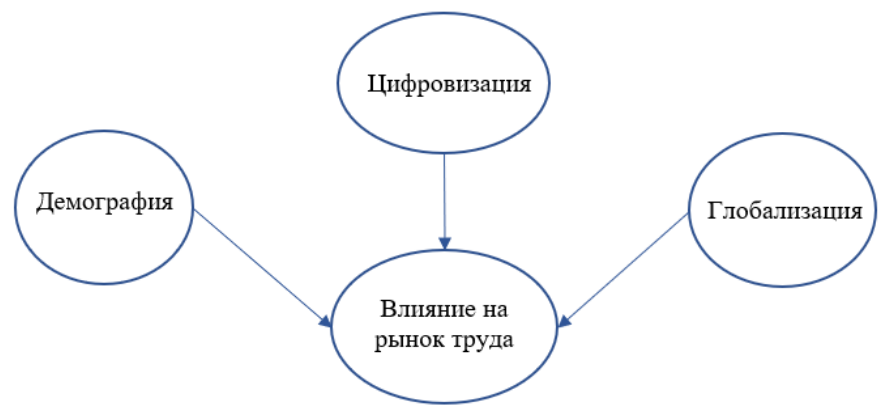

Рис. 1. Факторы, влияющие на рынок труда

Демографическое развитие является одним из важнейших факторов, влияющих на рынок труда, поскольку, помимо показателей численного состава населения, также экономические, социальные и природные условия и наравне с ними политические изменения и миграции определяют уровень рабочей силы.

Страны, имеющие явные преимущества в производстве определенных линеек товаров или в предоставлении некоторых услуг, стараются занять лидирующие позиции на мировом рынке. Таким образом, на первый план выходит глобализация, связанная непосредственно с международной миграцией, а также вопросы регулирования международных трудовых отношений.

Наряду с рассмотренными факторами одним из ключевых показателей является цифровизация бизнеса, а также экономики в целом, влияющая как на экономический 
E. В. Аксенюшкина, Н. В. Мамонова, А. В. Аксенюшкин. Влияние цифровизации экономики на рынок занятости в Иркутской области

рост, так и производительность. Некоторые ученые считают, что цифровизация является синонимом такого понятия, как «автоматизация», другими словами, выполнение производственных задач без помощи человека. Такой подход является достаточно однобоким, не отражающим полностью всю глубину такого глобального процесса. Более полным понятием цифровизации экономики является процесс, осуществляющий улучшение обслуживания или увеличение доходов на основе использования цифровых технологий и анализа данных, полученных при обработке показателей бизнес-процессов. Любой из этих подходов порождает потенциал для положительного воздействия на создание новых рабочих мест.

Проведем исследование влияния внедрения цифровизации в разные организации, которые активно используют персональные компьютеры и, как следствие, локальную сеть, электронную почту, интернет и т. д. Интерес представляет степень влияния компьютерных технологий на общие уровни безработицы и занятости населения Иркутской области [4; 5].

Было проведено исследование временных выборок уровня безработицы и уровня занятости в Иркутской области с 2005 по 2019 г. ${ }^{1}$ Основная задача состояла в определении статистической значимости зависимостей этих уровней от цифровизации ряда организаций, занимающихся экономической деятельностью.

В качестве объясняющих факторов рассматривались организации, в которых активно используются персональные компьютеры, локальные и глобальные сети, электронная почта, веб-сайты. Как показало исследование, наличие в организациях глобального интернета на уровни безработицы или занятости влияет не существенно. Кроме того, уровень безработицы был рассмотрен в качестве объясняемой переменной в зависимости от информационной среды. Казалось бы, интернет-технологии, наличие огромного количества инновационных компьютерных программ, а также интерес к глобальной сети Интернет должны были привести к снижению уровня безработицы из-за возможностей, связанных с цифровизацией. Однако результаты получились необычными: уровень безработицы снижается, но это зависит от других факторов (рис. 2).

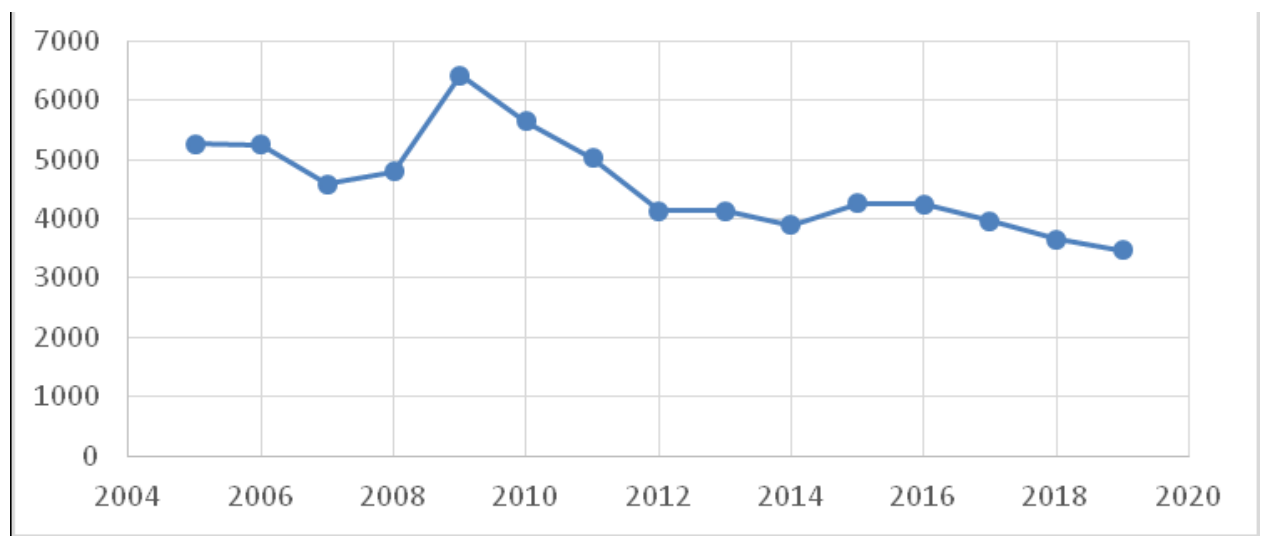

Рис. 2. Уровень безработицы в Иркутской области

\footnotetext{
1 Федеральная служба государственной статистики. URL: http:/www.gks.ru (дата обращения: 10.03.2021). Текст: электронный.
} 
Рассмотрим следующие обозначения УБ- уровень безработицы в Иркутской области; ПК - наличие персональных компьютеров в различных организациях (\%); ЛС - локальные сети; ЭП - электронная почта у сотрудников в этих организациях; ГИ - глобальный интернет, возможность выхода сотрудниками организаций в интернет; $B C$ - наличие у организации веб-сайтов.

Результаты корреляционного анализа приведены в таблице 1.

Таблица 1

\begin{tabular}{|c|c|c|c|c|c|c|}
\hline & УБ & $П К$ & $Л С$ & ЭП & $Г И$ & $B C$ \\
\hline$У Б$ & 1 & & & & & \\
\hline$П К$ & 0,18380727 & 1 & & & & \\
\hline$Л C$ & $-0,2743745$ & 0,067206 & 1 & & & \\
\hline$Э П$ & $-0,5768822$ & $-0,18334$ & 0,699335 & 1 & & \\
\hline$\Gamma И$ & $-0,5749883$ & $-0,19468$ & 0,727487 & 0,991572 & 1 & \\
\hline$B C$ & $-0,7810519$ & $-0,19821$ & 0,508951 & 0,90957 & 0,899363 & 1 \\
\hline
\end{tabular}

Из данной таблицы очевидно, что между общим уровнем безработицы и уровнем всех компьютерных технологий нет статистически значимой и существенной зависимости. Лишь наличие веб-сайтов у рассматриваемых организаций косвенно влияет на то, что безработные заинтересовываются и устраиваются на соответствующую работу, тем самым понижая показатель уровня безработицы.

Регрессионный анализ показал, что построенные модели не несут статистически значимой информации по снижению уровня безработицы.

Приведем одну из моделей, которая описывает зависимость уровня безработицы (УБ) от всех рассмотренных факторов:

УБ $=680,6+28,1$ ПК - 22,3 ЛС +81,9 ЭП-2,4 ГИ-106,2 ВС

Все построенные параметры этой модели статистически не значимы, имеют очень большие стандартные ошибки, модель в целом имеет достаточно высокий уровень $p$-значимости $(p \geq 0,05)$, что является показателем того, что модель в целом также статистически не значима, хоть и коэффициент детерминации достаточно высок. Варьирование факторов влияния на уровень безработицы не принес желаемых результатов [7; 8].

Следующим этапом исследователями было решено проанализировать поведение уровня занятости (УЗ) в Иркутской области, построить регрессионные модели и попытаться спрогнозировать данные по занятости.

График уровня занятости показал, что он достаточно хаотичен и зависит от разных факторов (рис. 3).

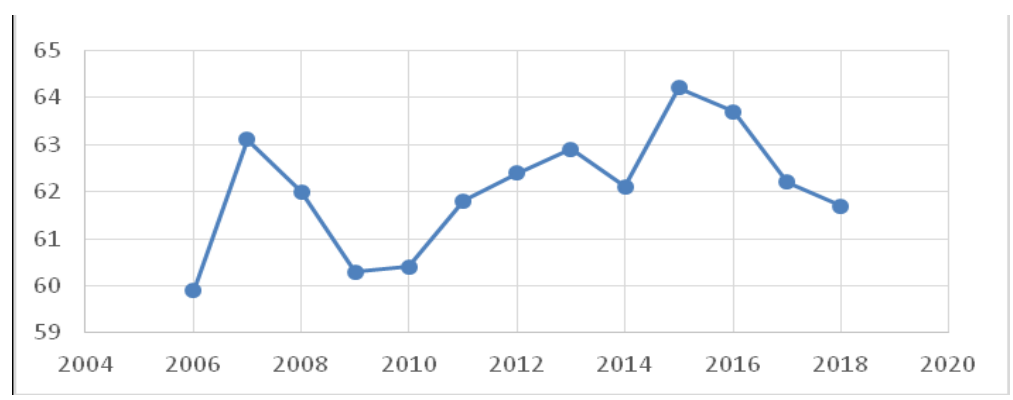

Рис. 3. Уровень занятости населения в Иркутской области 
E. В. Аксенюшкина, Н. В. Мамонова, А. В. Аксенюшкин. Влияние цифровизации экономики на рынок занятости в Иркутской области

Проведем регрессионный анализ, учитывая, что все переменные рассматриваются в одной системе уравнений:

$$
\begin{aligned}
& \text { УЗ }=177,1-1,04 \Pi К+0,188 \text { ЛС }-0,39 \text { ЭП }-0,073 \text { ГИ }+0,25 \text { ВС } \\
& \text { p- зн.: }(0,00005) \quad(0,0008) \quad(0,017) \quad(0,021) \quad(0,602) \quad(0,001)
\end{aligned}
$$

Очевидно, что все параметры модели статистически значимы, ( $p-$ значимость у всех меньше 0,05), кроме параметра при факторе - «глобальный интернет», но это несущественно, т. к. модель без этого фактора также показала себя с лучшей стороны. Коэффициент детерминации $\mathrm{R}^{2}=0,88$, что свидетельствует о высоком качестве построенной модели, и сама модель в целом также статистически значима, наблюдаемая точка критерия Фишера $\mathrm{F}_{0}=10,45$ достаточно высокая (

Анализируя построенную модель, приходим к следующему выводу: увеличить уровень занятости населения Иркутской области возможно за счет совершения ряда шагов, направленных на дальнейшее развитие цифровизации, а именно: более активное использование локальных сетей организации, обязательную разработку веб-сайтов организации, а также с целью информационной безопасности внедрение корпоративной почты. Структура модели указывает на уменьшение количества персональных компьютеров в организации что свидетельствует в пользу удаленной работы сотрудников. Использование для выполнения ряда работ фрилансеров, несомненно, является, исходя из реалий сегодняшнего времени, очень распространенным видом деятельности.

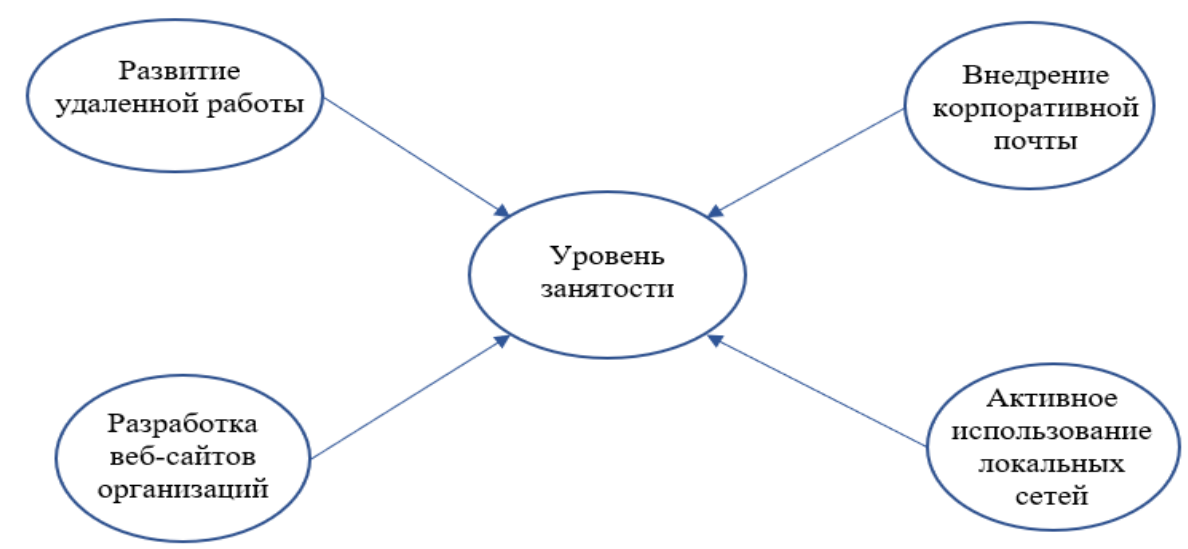

Рис. 4. Факторы, влияющие на уровень занятости населения

Интеллектуальный анализ данных, искусственный интеллект, трехмерная печать, облачные хранилища и многое другое являются «одним из событий, радикально меняющих перспективы для типов рабочих мест, которые понадобятся в будущем, а также где и кем они будут осуществляться» [9].

Новое время показало, что понятия «профессия» и «стабильная занятость» стали включать в себя уже новый смысл. Поскольку сегодня происходит постепенное замещение одних востребованных ранее профессий на другие, то только постоянное саморазвитие, получение нового образования и развитие новых компетенций смогут дать уверенность в завтрашнем дне. 
Постоянная цифровая трансформация различных бизнес-процессов оказала достаточно серьезное влияние на рынок труда, поэтому, опираясь на данные последних двадцати лет, было выявлено, что наиболее востребованными стали профессии, связанные с цифровыми технологиями (рис. 5).

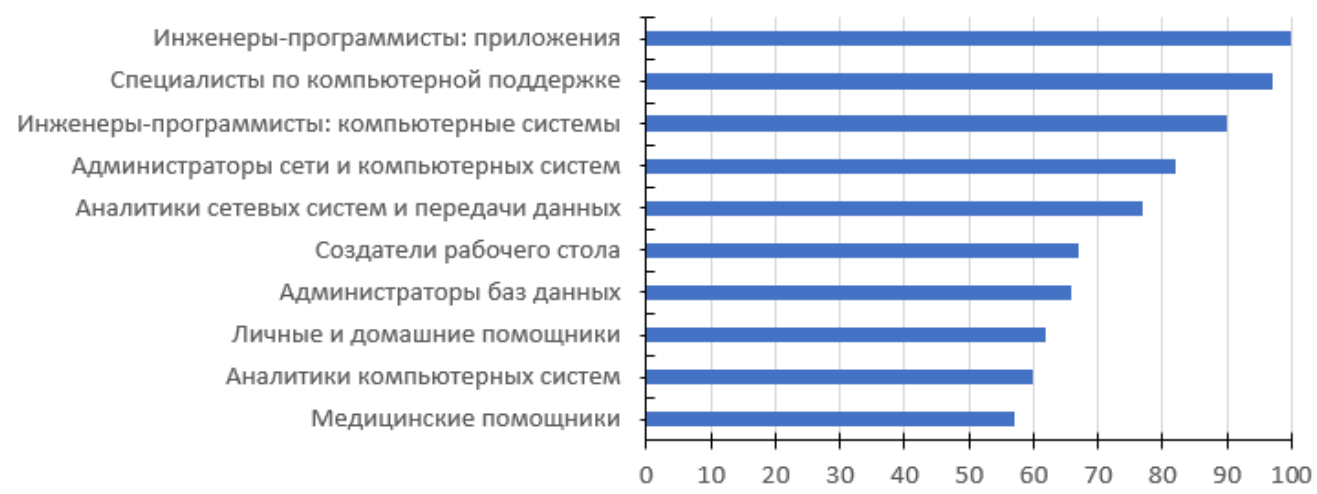

Рис. 5. Данные статистики труда о востребованных профессиях

(10 самых быстрорастущих профессий в мире), в \%

Цифровая трансформация экономики уже принесла с собой ряд глобальных изменений, создав новые профессии, такие как менеджер социальных сетей, специалист по облачным вычислениям, разработчик приложений и многие другие [10-12]. Наряду с этим упал спрос на низкоквалифицированные рабочие места, где выполнение работ можно автоматизировать. Естественно, что информационные технологии очень полезны и даже необходимы при выполнении некоторых задач, но какими бы развитыми они ни были, полностью заменить человека не представляется возможным. Очевидно, что гипотезы о повсеместной безработице вследствие развития цифровизации экономики являются несостоятельными. Пока еще невозможно предсказать, насколько сильное влияние окажет этот процесс на рынок труда, но происходящие изменения открывают достаточно широкие горизонты для исследования этой проблемы.

\section{Литература}

1. Балдынова Е. В., Малютина С. А. Сравнительный анализ среднемесячной реальной заработной платы работников организаций в разрезе видов экономической деятельности по Иркутской области // Известия Байкальского государственного университета. 2018. T. 28, № 3. C. 409-418. DOI: 10.17150/2500-2759.2018.28(3).409-418. Текст: непосредственный.

2. Рогачева О. А. Динамика доходов населения Иркутской области в начале 21 века // Современное состояние и перспективы развития бухгалтерского учета, экономического анализа и аудита: материалы международной научно-практической конференции, Иркутск, 23 апр. 2016 г. / под научной редакцией Е. М. Сорокиной. Иркутск: Изд-во Бурят. гос. ун-та, 2016. С. 303-309. Текст: непосредственный.

3. Колесникова О. А., Маслова Е. В. Занятость населения как фактор социальной стабильности // Вестник Воронеж. гос. ун-та. Сер.: Экономика и управление. 2015. № 4. С. 123-126. Текст: непосредственный. 
E. В. Аксенюшкина, Н. В. Мамонова, А. В. Аксенюшкин. Влияние цифровизации экономики на рынок занятости в Иркутской области

4. Соколова Л. Г., Казанцева И. И. Оценка резервного потенциала для стратегического планирования социально-экономического развития региона // Известия Байкальского государственного университета. 2020. Т. 30, № 4. С. 541-550. DOI: 10.17150/25002759.2020.30(4).541-550. Текст: непосредственный.

5. Наумова М. В. Социальные сети в локальной территориальной общности // Регион: экономика и социология. 2007. № 2. С. 113-120. Текст: непосредственный.

6. Леонова О. В. Моделирование смертности населения с помощью аналитических законов на примере России // Известия Байкальского государственного университета. 2019. Т. 29, № 1. С. 95-106. DOI: 10.17150/2500-2759.2019.29(1)/95-106. Текст: непосредственный.

7. Хавинсон М. Ю., Кулаков М. П. Математическое моделирование динамики численности разновозрастных групп, занятых в экономике региона // Компьютерные исследования и моделирование. 2014. Т. 6, № 3. С. 441-454. Текст: непосредственный.

8. Calvo-Armengol A. Social Networks and Labor Market Outcomes // Els Opuscules del CREI. 2006. № 17. 25 p.

9. Watts D. J., Strogatz S. H. Collective dynamics of "small-world" networks // Nature. 1998. Vol. 393. P. 440-442.

10. Былков В. Г. Повышение эффективности использования трудового потенциала в процессе актуализации системы оценки квалификаций // GLOBAL AND REGIONAL RESEARCH. 2019. T. 1, № 3. С. 76-81. Текст: непосредственный.

11. Коровкин А. Г. Проблемы согласования спроса на рабочую силу и ее предложения на российском рынке труда // Проблемы прогнозирования. 2011. № 2. С. 103-123. Текст: непосредственный.

12. Bramoulle Y., Saint-Paul G. Social Networks and Labor Market Transitions // IZA Discussion Paper. 2004. № 1215. 38 p.

Статья поступила в редакциию 04.04.2021; одобрена после рецензирования 28.04.2021; принята к публикаиии 28.04.2021.

\section{IMPACT OF ECONOMY DIGITALIZATION ON THE LABOUR MARKET OF IRKUTSK OBLAST}

Elena V. Aksenyushkina

Cand. Sci. (Phys. and Math.),

A/Prof. of Mathematical Methods and Digital Technologies Department

aks.ev@mail.ru

Natalya $V$. Mamonova

Cand. Sci. (Phys. and Math.),

A/Prof. of Mathematical Methods and Digital Technologies Department naamm@mail.ru

Aleksandr V. Aksenyushkin

Research Assistant of Mathematical Methods and Digital Technologies Department aksalekshd@gmail.com

Baikal State University

11 Lenina St., Irkutsk 664003, Russia

Abstract. Modern economy is following the path of widespread use of digital technologies that completely change many business processes. The study of the impact of digitalization 
on labour market, in particular on the level of employment and unemployment, is the most relevant today. Correlation analysis allows us to single out the main factors that characterize the processes of economy digitalization affecting the unemployment rate in Irkutsk Oblast. Time-series analysis is used to predict the labour market behavior. Based on the econometric research, we have identified the elements of digitalization that have the strongest impact on the employment rate of population in Irkutsk Oblast. The data analysis made it possible to show the inconsistency of the hypothesis about the negative impact of economy digital transformation on the level of population employment.

Keywords: labour market, unemployment rate, economy digitalization, econometric model, regression analysis, impact factors

For citation

Aksenyushkina E. V., Mamonova N. V., Aksenyushkin A. V. Impact of Economy Digitalization on the Labour Market of Irkutsk Oblast. Bulletin of Buryat State University. Economy and Management. 2021; 2: 3-10 (In Russ.).

The article was submitted 04.04.2021; approved after reviewing 28.04.2021; accepted for publication 28.04.2021. 